\title{
Abordagem Fuzzy Para a Dinâmica Populacional do Parque Nacional Montanhas do Tumucumaque
}

\author{
Thiago Fernando Ferreira \\ Universidade de Uberaba - UNIUBE, \\ 38408-343, Câmpus Uberlândia, Uberlândia, MG \\ E-mail: thiago.ferreira@uniube.br,
}

\author{
Neylan Leal Dias ${ }^{1}$ \\ Faculdade de Matemática, FAMAT, UFU, \\ 38408-100, Uberlândia, MG \\ E-mail: neylan@mestrado.ufu.br.
}

\section{RESUMO}

Os modelos populacionais tratam de variações das densidades de população, visando a melhor compreensão da variação do número de indivíduos de uma população e dos fatores que os influenciam.

O Parque Nacional Montanhas do Tumucumaque é o maior parque de floresta tropical do mundo e está localizado, em sua maior porção, no estado do Amapá. Estudamos neste trabalho o crescimento populacional das cidades ao redor do Parque utilizando o Modelo de Crescimento Populacional de Malthus, com o objetivo de modelar o crescimento da população, obtendo informações que poderão ser utilizadas por especialistas na tomada de decisões em relação à urbanização e à preservação do mesmo. Em seguida, utilizamos a variação per capita e a população inicial do modelo clássico em um sistema p-fuzzy (parcialmente fuzzy [2]) para comparar os resultados obtidos.

A Teoria dos Conjuntos Fuzzy foi introduzida por Lofti A. Zadeh em meados dos anos 60, com a intenção de dar um tratamento matemático a termos linguísticos subjetivos como "aproximadamente". A utilização de parâmetros fuzzy em equações diferenciais ganhou espaço na modelagem matemática de fenômenos naturais quando não dispomos de dados suficientes para adotar métodos estocásticos ou então quando a situação não comporta medidas e dependemos apenas de informações de especialistas.

O modelo clássico de Malthus e sua solução são representados, respectivamente, por

$$
\frac{d N}{d t}=r N \quad e \quad N(t)=N_{0} e^{r t}
$$

onde $N_{0}$ é a população inicial, $t$ a variação do tempo e $r$ a taxa de variação per capita.

Neste trabalho, a taxa $r$ é obtida pela fórmula $r=\sqrt[m]{\frac{P_{t}}{P_{i}}}-1$, onde $P_{i}$ representa a população inicial, $P_{t}$ a população final e $m=t-i[1]$.

A partir do censo do IBGE, dados coletados de alguns anos entre 1996 e 2010, do número de habitantes das cinco cidades localizadas ao redor do Parque, determinamos $r$ para cada cidade nos intervalos de tempo convenientes. Em seguida, calculamos a média aritmética dessas taxas para cada intervalo de tempo (Tabela 1). O valor $r=0,048$ foi calculado através da média aritmética dos dados da Tabela 1.

\begin{tabular}{|c|c|c|c|c|c|}
\hline Ano & $1996-2000$ & $2000-2002$ & $2002-2003$ & $2003-2007$ & $2007-2010$ \\
\hline Taxa de Variação Per Capita & 0,05662 & 0,04349 & 0,03769 & 0,05199 & 0,05251 \\
\hline
\end{tabular}

Tabela 1: Tabela da variação per capita em cada intervalo de tempo.

Consideramos a população inicial $N_{0}=44735$ a partir da Tabela 2, que apresenta a soma das populações das cinco cidades ao redor do Parque por ano.

\footnotetext{
${ }^{1}$ bolsista de Mestrado PICME/UFU
} 


\begin{tabular}{|c|c|c|c|c|c|c|}
\hline Ano & 1996 & 2000 & 2002 & 2003 & 2007 & 2010 \\
\hline População & 44735 & 55433 & 60183 & 62387 & 74551 & 84603 \\
\hline
\end{tabular}

Tabela 2: Soma das populações das cidades ao redor do Parque.

Para o sistema p-fuzzy de Malthus, utilizamos as funções de pertinência das Figuras 1 e 2, o método de inferência de Mamdani e para defuzzificação o centro de gravidade. Para o modelo fuzzy, o método numérico utilizado foi Euler e o número de iterações foi $n=140 \operatorname{com} \Delta t=0,1$.

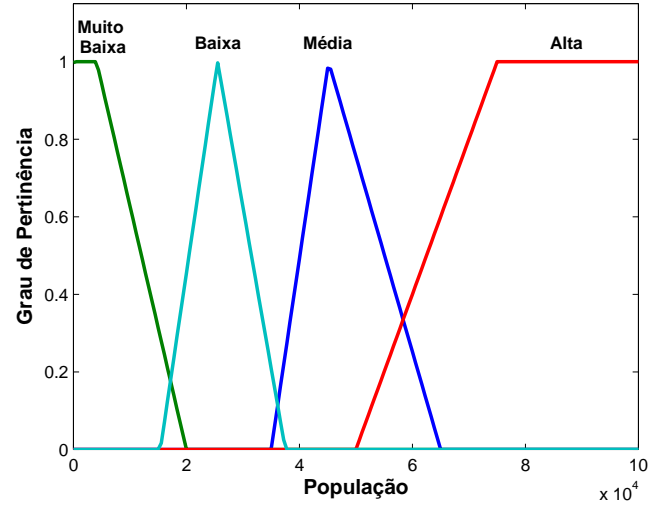

Figura 1: Funções de Pertinência de Entrada.

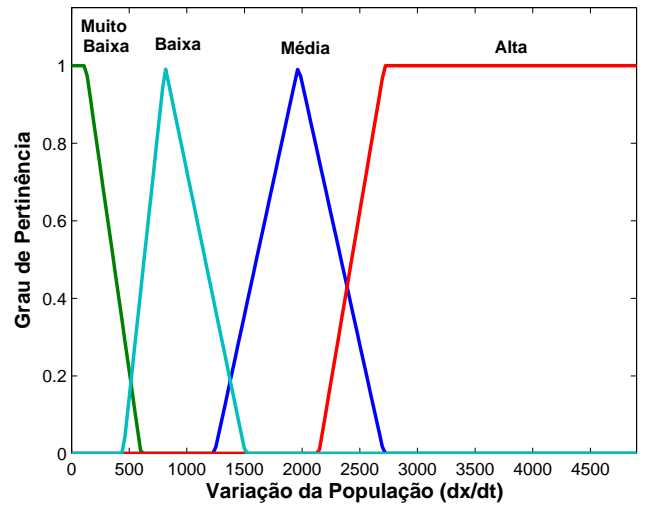

Figura 2: Funções de Pertinência de Saída.

A Figura 3 representa os gráficos dos modelos clássico e fuzzy, e a Figura 4 o erro relativo.

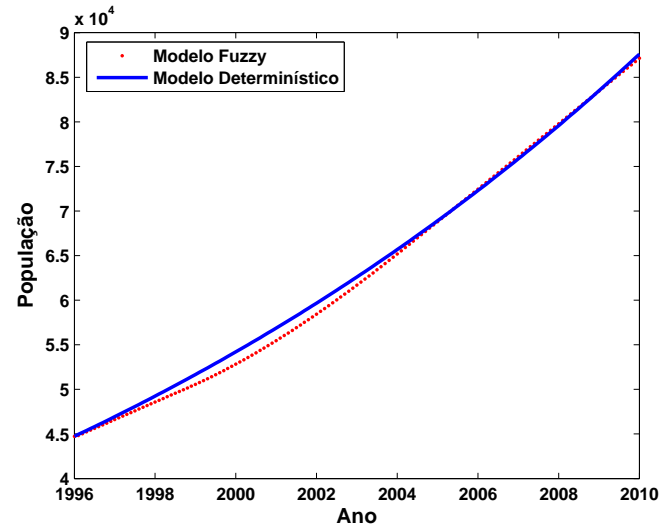

Figura 3: Crescimento da População.

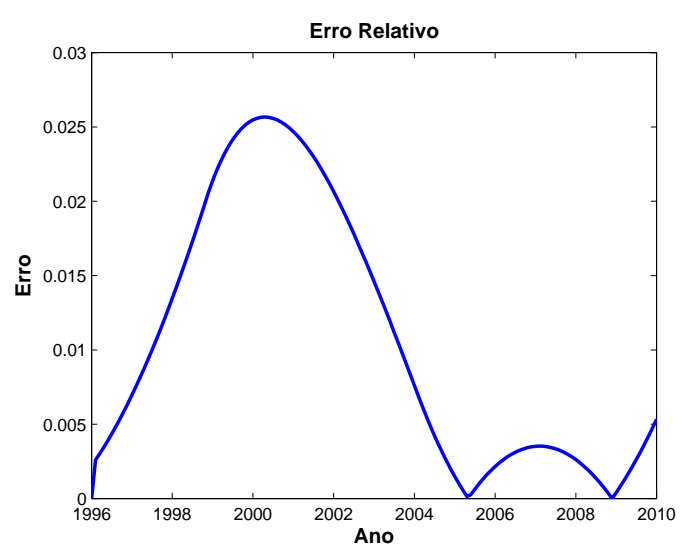

Figura 4: Erro Relativo.

Podemos observar que o erro obtido entre os modelos é mínimo, mostrando que ambos podem ser utilizados para essa situação. Como o crescimento da população pode ser estimado por meio desses modelos, eles podem ser úteis na tomada de decisões sobre a urbanização, meios de preservação e projetos de utilização responsável da área do Parque pela população local.

Palavras-chave: Dinâmica Populacional, Teoria dos Conjuntos Fuzzy, Modelagem Matemática.

\section{Referências}

[1] N.L. Dias, "Modelagem Matemática de Problemas Biológicos", Trabalho de Conclusão de Curso, Universidade Federal do Amapá, Macapá, 2013.

[2] T.F. Ferreira, "Sistemas p-Fuzzy Modificados para Dinâmicas Populacionais: modelagens e simulações”, Dissertação de Mestrado, Famat-UFU, Uberlândia-MG, 2012. 